\title{
In Focus
Spotlight on the September 16 Issue
}

Robert A. Gross, MD, PhD, FAAN

Editor-in-Chief, Neurology ${ }^{\circledR}$

\section{Genetics of epilepsy: The testimony of twins in the} molecular era

Analysis of 418 twin pairs enabled improved understanding of the genetic architecture of epilepsy syndromes and emphasized the utility of the 2010 International League Against Epilepsy organizational system. Selected conventional molecular testing revealed relevant variants in $10 \%$ of cases. These data are critical for strategic planning for large-scale next-generation sequencing studies.

See p. 1042

From editorialists Guerrini \& Buchhalter: "As next-generation sequencing in large cohorts emerges, complexities in the genetic basis of epilepsy, as underlined by twin studies, should be kept in mind."

See p. 1038

\section{Rasmussen encephalitis and comorbid autoimmune diseases: A window into disease mechanism?}

The authors report a case series of 4 patients with Rasmussen encephalitis in whom a comorbid autoimmune disease was diagnosed. The association of Rasmussen encephalitis with a comorbid autoimmune disease raises the possibility of shared mechanisms of susceptibility, including common immunogenetic or environmental risk factors.

See p. 1049

\section{Bulbar muscle MRI changes in patients with SMA with} reduced mouth opening and dysphagia

The authors examined 145 patients with spinal muscular atrophy (SMA) types 1-4 and 119 controls and used MRI in 12 of the patients to visualize mandibular condylar shape and sliding along with anatomy of muscle groups. Reduced maximal mouth opening was common in SMA types 1-3a and was caused by fatty degeneration of specific mouth opening muscles.

See p. 1060

\section{Functional pattern of brain FDG-PET in amyotrophic}

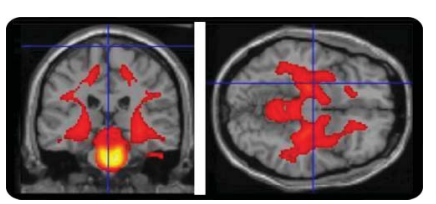

\section{lateral sclerosis $\mathbb{E}[$ 슬}

A total of 195 patients with amyotrophic lateral sclerosis (ALS) and 40 controls underwent brain ${ }^{18}$ F-FDG PET. Hypometabolism was found in frontal, motor, and occipital cortex and hypermetabolism in midbrain, temporal pole, and hippocampus in patients with ALS compared to controls. With replication, the present methodology may represent a potentially useful additional biomarker for ALS diagnosis.

See p. 1067
Increased risk of osteoporosis in patients with myasthenia gravis: A population-based cohort study

In analyzing $99 \%$ of the population of Taiwan, evidence showed that a myasthenia gravis (MG) cohort of 2,073 patients had a 1.96-fold increased risk of developing osteoporosis. Because MG was associated with a high risk of osteoporosis, screening patients with MG at the time of initial diagnosis may allow for prophylactic interventions that improve bone health.

See p. 1075

\section{Lower wake resting sympathetic and cardiovascular activities in narcolepsy with cataplexy}

Microneurography disclosed lower awake resting sympathetic activity together with lower heart rate and blood pressure in 19 patients with narcolepsy with cataplexy (NC) compared to controls. Wake autonomic activity in NC was correlated with hypocretin-1 deficiency, supporting a direct hypocretin effect on autonomic dysfunctions.

See p. 1080

Course of psychiatric symptoms and global cognition in early Parkinson disease :-

This study evaluated the course and predictors of neuropsychiatric symptoms (NPS) and cognition in a cohort of de novo, untreated patients with Parkinson disease (PD) and controls from the Parkinson's Progression Markers Initiative. Multiple NPS were more common in de novo, untreated patients with PD compared with the general population, but they remained relatively stable in early disease, while global cognition slightly deteriorated.

See p. 1096

NB: "Primary intracranial plasma cell granuloma responsive to rituximab," see p. 1119. To check out other Clinical/Scientific Notes, point your browser to Neurology.org. 


\title{
Neurology
}

\author{
Spotlight on the September 16 Issue \\ Robert A. Gross \\ Neurology 2014;83;1037 \\ DOI 10.1212/WNL.0000000000000847
}

This information is current as of September 15, 2014

\section{Updated Information \&}

Services

Permissions \& Licensing

Reprints including high resolution figures, can be found at: http://n.neurology.org/content/83/12/1037.full

Information about reproducing this article in parts (figures,tables) or in its entirety can be found online at:

http://www.neurology.org/about/about_the_journal\#permissions

Information about ordering reprints can be found online:

http://n.neurology.org/subscribers/advertise

Neurology ${ }^{\circledR}$ is the official journal of the American Academy of Neurology. Published continuously since 1951, it is now a weekly with 48 issues per year. Copyright () 2014 American Academy of Neurology. All rights reserved. Print ISSN: 0028-3878. Online ISSN: 1526-632X.

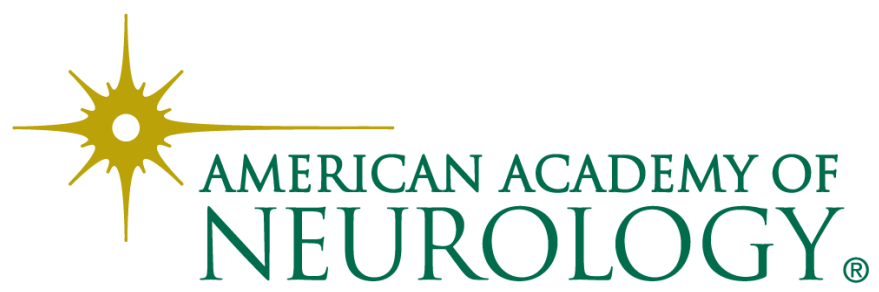

